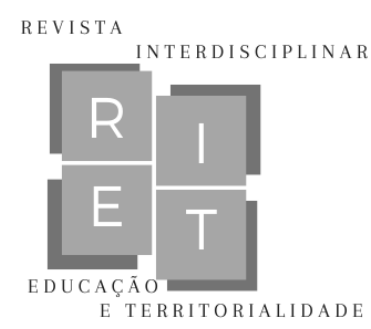

\title{
A Gestão Educacional da Educação do Campo durante os Tempos de Pandemia no município de São Gabriel/RS/Brasil
}

\author{
The Educational Management of Rural Education during the Pandemic Times \\ in the municipality of São Gabriel/RS/Brazil
}

\author{
La Gestión Educativa de la Educación Rural durante la Época de la \\ Pandemia en el Municipio de São Gabriel/RS/Brasil
}

\begin{abstract}
Eduardo Pastorio
Programa de Pós-graduação em Educação em Ciências, Universidade Federal do Rio Grande do

Sul (UFRGS)

São Gabriel, RS, Brasil

E-mail: eduardopastorio@ @otmail.com

ORCID: https://orcid.org/0000-0003-2342-7851
\end{abstract}

José Vicente Lima Robaina

Programa de Pós-Graduação em Educação em Ciências, Universidade Federal do Rio Grande do

Sul (UFRGS)

Porto Alegre, RS, Brasil

E-mail: joserobaina1326@gmail.com

ORCID: https://orcid.org/0000-0002-4604-3597

\begin{abstract}
Resumo: O presente texto tem como objetivo identificar e apresentar as principais estratégias adotadas na oferta da Educação do Campo, no contexto da gestão educacional da Secretaria Municipal de Educação (SEME) às 8 Escolas Municipais do Campo, durante os tempos de pandemia em 2020, com a suspensão das aulas presenciais na rede municipal de ensino e o desenvolvimento das Atividades Pedagógicas Não Presenciais. Trata-se de uma pesquisa explicativa, de abordagem qualitativa, utilizando da técnica de estudo de caso e de pesquisa-ação. A suspensão ocorreu em 19 de março de 2020, através de Decreto Executivo, e a partir dessa data, a SEME iniciou planejamento para execução da oferta da educação durante o período, com publicações de Ordens de Serviço e elaboração do Plano de Ação Pedagógica. Além disso, registra-se que ocorreu contínuo monitoramento pelo Conselho Municipal de Educação (CME), apreciando e deliberando sobre as ações executadas, através de Pareceres. Com destaque, verificou-se a execução às Escolas do Campo de: 1 - Atividades Pedagógica Não Presenciais (Ensino Remoto), com entrega de atividades quinzenais no local de embarque do transporte escolar ou na residência dos estudantes; 2 - Projeto "São Gabriel - minha cidade educadora", explorando o conceito de Cidade Educadora, quando do ingresso do município na Associação Internacional de Cidades Educadoras; e 3 - Programa Rádio Educação, com inserções diárias das direções e professores nas emissoras de rádios locais sobre diferentes temas pedagógicos, direcionado aos estudantes e suas famílias.
\end{abstract}

Palavras-chave: Educação do Campo. Gestão Educacional. Tempos de Pandemia. 


\section{A Gestão Educacional da Educação do Campo durante os Tempos de Pandemia no município de São Gabriel/RS/Brasil}

Abstract: This text aims to identify and present the main strategies adopted in the offer of Education in the Countryside, in the context of the educational management of the Municipal Education Secretariat (SEME) to the 8 Municipal Schools in the Countryside, during the pandemic times in 2020, with the suspension of face-to-face classes in the municipal school system and the development of non-face-to-face pedagogical activities. This is an explanatory research, with a qualitative approach, using the technique of case study and action research. The suspension took place on March 19, 2020, through Executive Decree, and from that date, SEME began planning to implement the education offer during the period, with publication of Service Orders and preparation of the Pedagogical Action Plan. In addition, it is registered that there was continuous monitoring by the Municipal Education Council (CME), assessing and deliberating on the actions carried out, through Opinions. With emphasis, the execution of the Schools of the Field was verified of: 1 - Pedagogical Activities Not Presencial (Remote Teaching), with delivery of fortnightly activities in the place of departure of the school transport or in the residence of the students; 2 - Project "São Gabriel - my educating city", exploring the concept of Educating City, when the municipality joined the International Association of Educating Cities; and 3 - Radio Education Program, with daily insertions of the directors and teachers in the local radio stations on different pedagogical themes, aimed at students and their families.

Keywords: Rural Education. Educational Management. Pandemic Times.

Resumen: Este texto tiene como objetivo identificar y presentar las principales estrategias adoptadas en la oferta de Educación en el Campo, en el contexto de la gestión educativa de la Secretaría Municipal de Educación (SEME) a las 8 Escuelas Municipales del Campo, durante los tiempos pandémicos del 2020, con la suspensión de las clases presenciales en el sistema escolar municipal y el desarrollo de actividades pedagógicas no presenciales. Se trata de una investigación explicativa, con enfoque cualitativo, que utiliza la técnica del estudio de casos y la investigación-acción. La suspensión se llevó a cabo el 19 de marzo de 2020, mediante Decreto Ejecutivo, y a partir de esa fecha, la SEME comenzó a planificar la implementación de la oferta educativa durante el período, con publicación de Órdenes de Servicio y elaboración del Plan de Acción Pedagógica. Además, se registra que hubo un seguimiento continuo por parte del Consejo Municipal de Educación (CME), evaluando y deliberando sobre las acciones realizadas, a través de Dictámenes. Con énfasis, se verificó la ejecución de las Escuelas del Campo de: 1 - Actividades Pedagógicas No Presenciales (Educación Remota), con entrega de actividades quincenales en el lugar de salida del transporte escolar o en la residencia de los alumnos; 2 - Proyecto "São Gabriel - mi ciudad educadora", explorando el concepto de Ciudad Educadora, cuando el municipio se incorporó a la Asociación Internacional de Ciudades Educadoras; y 3 - Programa de Educación Radial, con inserciones diarias de los directores y docentes en las estaciones de radio locales sobre diferentes temas pedagógicos, dirigido a los estudiantes y sus familias.

Palabras Clave: Educación Rural. Gestión Educativa. Tiempos de Pandemia.

Data de recebimento: $15 / 04 / 2021$

Data de aprovação: 10/06/2021

DOI: $10.30612 /$ riet.v\%vi\%i.14557

\section{Introdução}

A Educação do Campo, depois de décadas definida como segundo plano na agenda política brasileira, vem registrando importantes avanços no cenário educacional, nas escalas 


\section{A Gestão Educacional da Educação do Campo durante os Tempos de Pandemia no município de São Gabriel/RS/Brasil}

federal, estadual e municipal, a partir de significativos movimentos sociais, políticos e acadêmicos, que reivindicavam a oferta da educação aos povos do campo. A partir desses movimentos, foram sendo implementadas políticas públicas específicas sobre o assunto, que culminaram para que além do acesso, houvessem melhorias significativas nas condições escolares às comunidades rurais durante as primeiras décadas do Século XXI.

Nesse movimento contínuo, que marcam períodos de avanços e retrocessos, surge ainda o desafio de agir sobre a suspensão das aulas presenciais, provocada com a expansão da pandemia do coronavírus (COVID-19). Nesse sentido, o presente texto tem como objetivo identificar e apresentar as principais estratégias adotadas na oferta da Educação do Campo, no contexto da gestão educacional da Secretaria Municipal de Educação (SEME) às 8 Escolas Municipais do Campo, durante os tempos de pandemia em 2020, com a suspensão das aulas presenciais na rede municipal de ensino e o desenvolvimento das Atividades Pedagógicas Não Presenciais.

A suspensão ocorreu em 19 de março de 2020, através de Decreto Executivo, e a partir dessa data, a SEME iniciou planejamento para execução da oferta da educação durante o período, com publicações de Ordens de Serviço e elaboração do Plano de Ação Pedagógica. Além disso, registra-se que ocorreu contínuo monitoramento pelo Conselho Municipal de Educação (CME), apreciando e deliberando sobre as ações executadas, através de Pareceres.

Com destaque, verificou-se a execução às Escolas do Campo de: 1 - Atividades Pedagógica Não Presenciais (Ensino Remoto), com entrega de atividades quinzenais no local de embarque do transporte escolar ou na residência dos estudantes; 2 - Projeto "São Gabriel - minha cidade educadora", explorando o conceito de Cidade Educadora, quando do ingresso do município na Associação Internacional de Cidades Educadoras; e 3 - Programa Rádio Educação, com inserções diárias das direções e professores nas emissoras de rádios locais sobre diferentes temas pedagógicos, direcionado aos estudantes e suas famílias.

Este artigo é parte resultante da pesquisa intitulada "Gestão Educacional, Currículo Escolar e Formação Continuada na Educação do Campo do município de São Gabriel/RS”, desenvolvida no âmbito do Curso de Doutorado do Programa de Pós-Graduação em Educação em Ciências na Universidade Federal do Rio Grande do Sul, a qual busca compreender, entre outros aspectos, o papel da Gestão Educacional para o desenvolvimento da Educação do Campo nas Escolas Municipais do Campo de São Gabriel/RS. 


\section{A Gestão Educacional da Educação do Campo durante os Tempos de Pandemia no município de São Gabriel/RS/Brasil}

\section{Percurso Metodológico e Teórico da Pesquisa}

Para o contexto metodológico, utilizou-se da pesquisa explicativa, buscando apresentar o contexto de São Gabriel no enfrentamento da pandemia na área da educação, em particular nas Escolas do Campo. Para Gil (2008), as pesquisas explicativas "são aquelas pesquisas que têm como preocupação central identificar os fatores que determinam ou que contribuem para a ocorrência dos fenômenos" e reforça que "este é o tipo de pesquisa que mais aprofunda o conhecimento da realidade".

Quanto a abordagem, a pesquisa é qualitativa, pois preocupa-se com "a natureza dos dados coletados, a extensão da amostra, os instrumentos de pesquisa e os pressupostos teóricos que nortearam a investigação" (GIL, 2008) e, como ferramenta para interpretar as informações coletadas, procura compreender as experiências visualizadas, as representações e os comportamentos, sendo que essas estruturas relatadas são as referências das análises e interpretações. (CHIZZOTTI, 1998).

No contexto da técnica, utilizou-se do estudo de caso, pois busca aprofundar todos os aspectos vinculados ao objeto de estudo em análise. Gil (2008), contribui ao definir como "estudo profundo e exaustivo de um ou de poucos objeto, de maneira a permitir o seu conhecimento amplo e detalhado". Considerando a atualidade do fenômeno, Yin (2011) reforça que estudo de caso investiga um fenômeno atual dentro do seu contexto de realidade, explorando, descrevendo e explicando situações do mundo real.

Também utilizou-se da técnica de pesquisa-ação, que para Gil (2008) "se caracterizam pelo envolvimento dos pesquisadores e dos pesquisados no processo de pesquisa" e para Thiollent (2005, p. 14) "é um tipo de pesquisa social com base empírica", "concebida e realizada em estreita associação com uma ação ou com a resolução de um problema coletivo" e "os pesquisadores e os participantes representativos da situação ou do problema estão envolvidos do modo cooperativo ou participativo".

No contexto da pesquisa, o primeiro autor é ocupante de cargo na SEME (inclusive esteve Coordenador das Escolas do Campo no período de 2017 a 2019) e é membro do CME, onde acompanhou e participou efetivamente no planejamento administrativo e pedagógico, construção dos projetos e nas normatizações do processo de desenvolvimento das atividades pedagógicas nas Escolas do Campo, durante a pandemia com suspensão das aulas presenciais.

97

RIET-ISSN 2676-0355, Dourados, v. 2, n. 2, p. 94 a 114, jan./jun., 2021 


\section{A Gestão Educacional da Educação do Campo durante os Tempos de Pandemia no município de São Gabriel/RS/Brasil}

Registra-se, como base teórica, Caldart (2012) que nomeia a Educação do Campo como "um fenômeno da realidade brasileira atual", traduz como "prática social ainda em processo de constituição histórica" e como conceito em construção,

[...] sem se descolar do movimento específico da realidade que a produziu, já pode configurar-se como uma categoria de análise da situação ou de práticas e políticas de educação dos trabalhadores do campo, mesmo as que se desenvolvem em outros lugares e com outras denominações. (CALDART, 2012, p. 259).

Para contribuir Kolling, Nery e Molina (1999) destacam que a construção de uma educação pensada a partir das vivências e dos interesses dos sujeitos pertencentes ao campo, com o objetivo de promover o desenvolvimento social e econômico, resgatar aspectos históricos e culturais, torna-se a escola como espaço de acolhimento, promoção de vida e emancipação social do sujeito.

Na trajetória dos documentos legais, cita-se Brasil (1988) que traz a educação como direito fundamental, e Brasil (1996) que define que na "oferta de educação básica para a população rural, os sistemas de ensino promoverão as adaptações necessárias à sua adequação às peculiaridades da vida rural", com "conteúdos curriculares e metodologias apropriadas", "organização escolar própria" e "adequação à natureza do trabalho na zona rural".

Como marco da política da Educação do Campo, temos Brasil (2002) com as “Diretrizes Operacionais para a Educação Básica nas Escolas do Campo", e Brasil (2008), com as "Diretrizes complementares, normas e princípios para o desenvolvimento de políticas públicas de atendimento da Educação Básica do Campo", como documentos que nortearam a oferta da educação aos povos do campo.

Com Brasil (2010a), a Educação do Campo tornou-se uma modalidade de ensino na estrutura educacional brasileira, reafirmando os dizeres da LDB e reforçando que "a identidade da escola do campo é definida pela vinculação com as questões inerentes à sua realidade, com propostas pedagógicas que contemplam sua diversidade em todos os aspectos, tais como sociais, culturais, políticos, econômicos, de gênero, geração e etnia". Para finalizar o contexto nacional, Brasil (2010b) trouxe a "Política de Educação do Campo", delimitando os cinco princípios para a educação do campo e ainda definiu o conceito de "escola do campo", como "aquela situada em área rural, conforme definida pela Fundação Instituto Brasileiro de Geografia e Estatística - IBGE, ou aquela situada em área urbana, 


\section{A Gestão Educacional da Educação do Campo durante os Tempos de Pandemia no município de São Gabriel/RS/Brasil}

desde que atenda predominantemente a populações do campo", e o conceito de "populações do campo" como:

[...] os agricultores familiares, os extrativistas, os pescadores artesanais, os ribeirinhos, os assentados e acampados da reforma agrária, os trabalhadores assalariados rurais, os quilombolas, os caiçaras, os povos da floresta, os caboclos e outros que produzam suas condições materiais de existência a partir do trabalho no meio rural;

No cenário municipal, citamos São Gabriel (2019) com a Resolução CME/SG N ${ }^{o}$ 009/2019, que "Dispõe sobre as Diretrizes Curriculares para Educação do Campo, no Sistema Municipal de Ensino de São Gabriel/RS"; São Gabriel (2020), com o Parecer CME/SG No 06, o Parecer CME/SG No 07 e o Parecer CME/SG No 14; e São Gabriel (2021), com o Parecer CME/SG No 005, sendo que todos pareceres aprovados são relacionados a reorganização do calendário escolar, em razão da pandemia e da suspensão das aulas presenciais, com a oferta de atividades pedagógicas não presenciais.

\section{Contextualizando o município e as Escolas do Campo de São Gabriel/RS/Brasil}

O município de São Gabriel localiza-se na Microrregião da Campanha Central e na Mesorregião Sudoeste Rio-Grandense, conhecida popularmente como a Campanha Gaúcha (Figura 01), próximo da fronteira com a Argentina e o Uruguai. No contexto dos 497 municípios do estado do Rio Grande do Sul é o $37^{\circ}$ maior em população (62 147 habitantes - estimativa IBGE/2020) e $6^{\circ}$ maior em área territorial $\left(5020 \mathrm{~km}^{2}\right)$.

Figura 01 - Mapa de localização de São Gabriel na Mesorregião Sudoeste do RS 99

RIET- ISSN 2676-0355, Dourados, v. 2, n. 2, p. 94 a 114, jan./jun., 2021 


\section{A Gestão Educacional da Educação do Campo durante os Tempos de Pandemia no}

município de São Gabriel/RS/Brasil

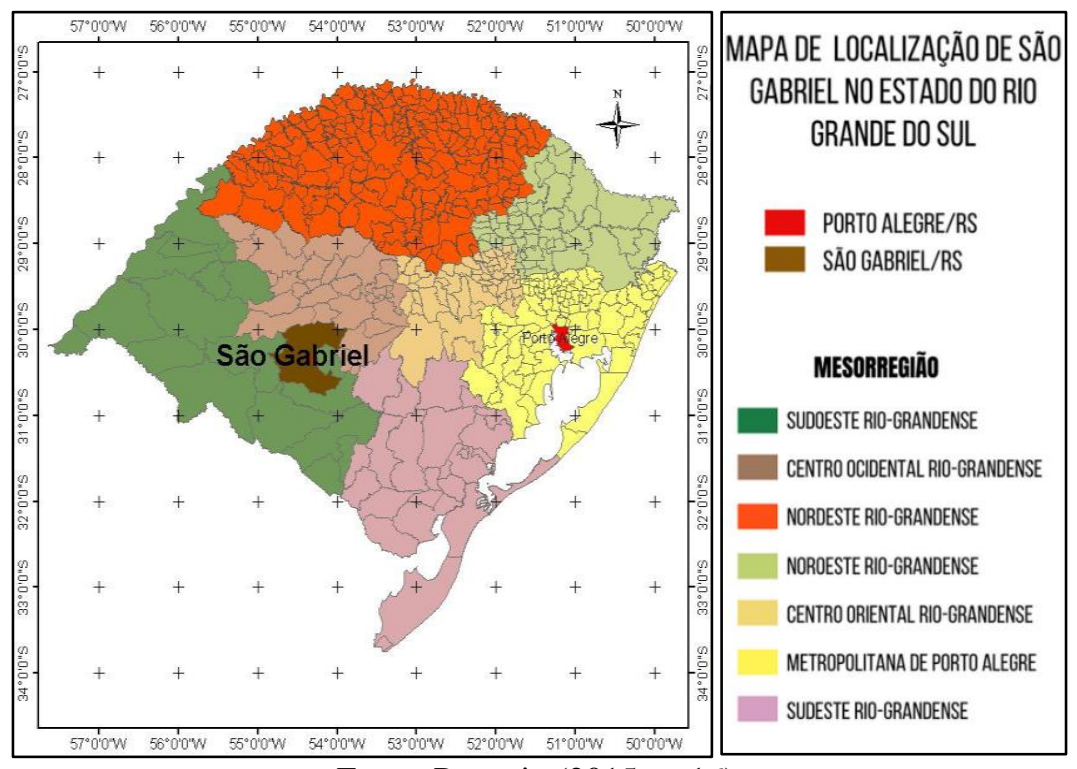

Fonte: Pastorio (2015, p. 16).

No contexto educacional, o município possui 63 instituições de ensino, sendo 37 Escolas Municipais e destas, 8 Escolas do Campo (Figura 02), que no município de São Gabriel são denominadas de Escola Municipal do Campo de Ensino Fundamental (EMCEF). Das 8 instituições, 3 são chamadas de Escolas Multisseriadas (EMCEF Catão Peres, EMCEF João Giuliani e EMCEF Victoria D’Ávila Chiappetta) e 5 são chamadas de Escolas Polos (EMCEF Baltazar Teixeira da Silveira, EMCEF Ernesto José Annoni, EMCEF Jerônimo Machado, EMCEF Maria Manoela da Cunha Teixeira, e EMCEF Mascarenhas de Moraes).

Figura 02 - Mapa das Escolas do Campo de São Gabriel/RS.

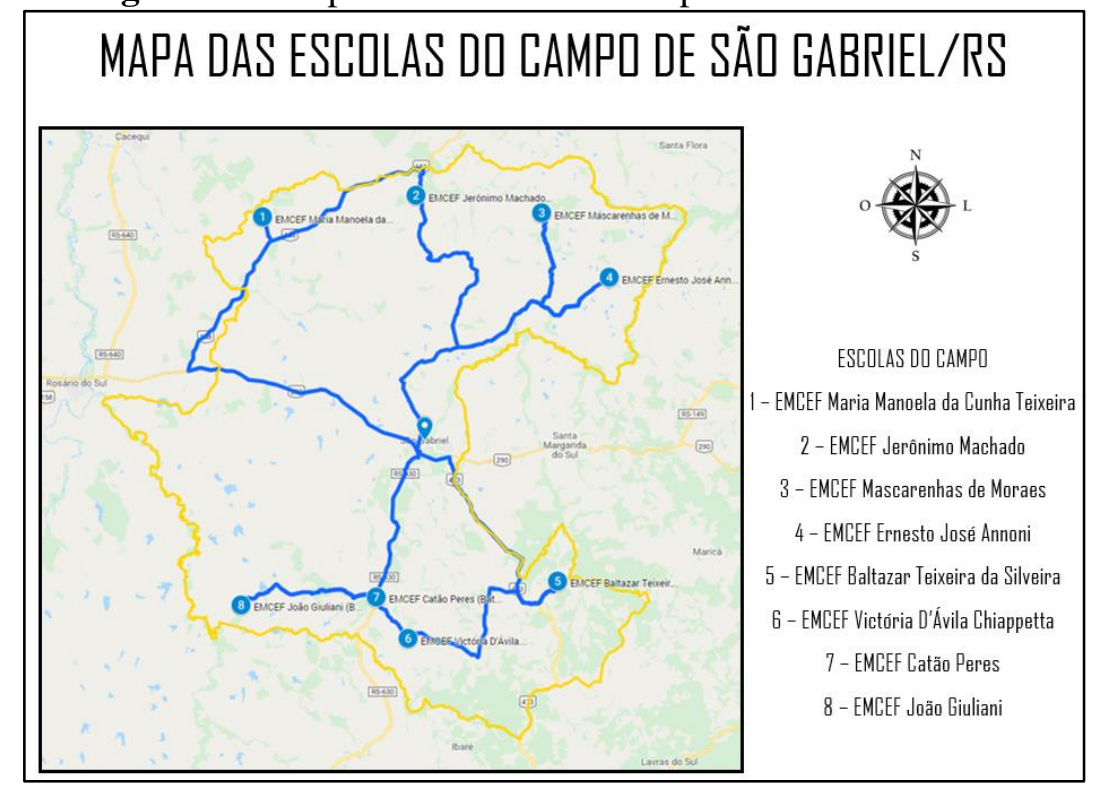

Fonte: Pastorio (2019, p. 217).

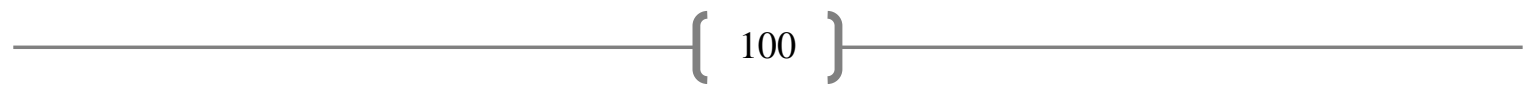

RIET- ISSN 2676-0355, Dourados, v. 2, n. 2, p. 94 a 114, jan./jun., 2021 


\section{A Gestão Educacional da Educação do Campo durante os Tempos de Pandemia no município de São Gabriel/RS/Brasil}

A espacialização atual das Escolas do Campo é reflexo do processo de nucleação, desenvolvido na década de 90 em São Gabriel, que segundo Pastorio (2015, p. 90) “[...] consistia no fechamento de pequenas escolas, ditas "isoladas" (na maioria, multisseriadas), agrupando-as em uma escola central (Nucleadas / Núcleos / Polos / Consolidadas)". Este projeto impactou 57 comunidades rurais, “(...) fechando 41 escolas (de menor porte/multisseriadas) e criando cinco novas escolas, denominadas de Escolas Polos", com a $1^{\circ}$ escola em 1992, depois criadas em sequência 1994, 1995 e 1996, com a última em 1999 (PASTORIO, 2015, p. 90).

Essas instituições de ensino possuem uma designação própria, sendo denominadas oficialmente de Escola Municipal do Campo de Ensino Fundamental (EMCEF), regulamentado pelo Decreto Executivo $\mathrm{N}^{\circ}$ 057, do dia 28 de agosto de 2018. (PASTORIO, 2019, p. 215). As escolas também aderem a um calendário letivo adaptado, respeitando as características físicas, sociais e econômicas de suas comunidades, com dias letivos integrais e alternados, onde cumprem-se as 800 horas previstas em lei, com flexibilização dos 200 dias letivos.

\section{Início da Pandemia e as Atividades Pedagógicas Não Presenciais nas Escolas Municipais}

O Ano Letivo de 2020 será marcado na história pela pandemia do novo coronavírus (COVID-19) e as consequências em todos os setores sociais, inclusive na educação. No município de São Gabriel, a primeira mudança foi a suspensão das aulas presenciais pelo Decreto Executivo $\mathrm{N}^{\circ}$ 024/2020, publicado no dia 19 de março de 2020 pela Prefeitura Municipal.

Naquele momento, o único objetivo da administração pública municipal era preservar a vida das nossas comunidades escolares. Ao mesmo tempo, a Secretaria Municipal de Educação iniciou estudos, considerando o acesso à educação como direito social fundamental previsto na Constituição Federal (1988) e na Lei de Diretrizes e Bases da Educação Nacional (1996), para encontrar amparo legal nas legislações vigentes e definir metodologias específicas ao contexto atual.

Como resultado, no objetivo de organizar o funcionamento e os procedimentos adotados para a manutenção da oferta da educação na rede municipal de ensino durante a suspensão das aulas presenciais, em decorrência da prevenção ao COVID-19, foi publicado 


\section{A Gestão Educacional da Educação do Campo durante os Tempos de Pandemia no município de São Gabriel/RS/Brasil}

a Ordem de Serviço $\mathrm{N}^{\circ}$ 002/2020, no dia 20 de março de 2020, que entre outros aspectos, definiu: "escolas [...] devem planejar e organizar as atividades a serem realizadas pelos estudantes fora da instituição"; "professores devem disponibilizar aos estudantes, trabalhos quinzenais, preferencialmente por meio eletrônico"; "entregar as atividades imediatamente após a suspensão das aulas"; e "os professores são a referência do processo de ensino e de aprendizagem".

Como complemento, o setor pedagógico elaborou o Plano de Ação Pedagógica, delimitando a proposta geral de execução das Atividades Pedagógicas Não Presenciais, e encaminhou para as Escolas Municipais, para que cada instituição procurasse adaptar ao seu contexto individual.

Para deliberar sobre o assunto, solicitamos ao Conselho Municipal de Educação, através do Ofício SEME Nº 040, de 20 de março de 2020, a análise sobre a Ordem de Serviço $\mathrm{N}^{\circ}$ 002/2020. Como resultado, foi aprovado o Parecer CME/SG $\mathrm{N}^{\circ}$ 006, de 25 de junho 2020, que "Determina as instituições pertencentes ao Sistema Municipal de Ensino sobre a reorganização do calendário escolar em virtude do Coronavírus (COVID-19) e o desenvolvimento excepcional das atividades escolares, enquanto permanecerem suspensas as aulas presenciais e o período pós-pandemia".

Nas conclusões do Parecer, determinou à mantenedora o envio do Plano de Ação para análise do CME. Cumprindo o dispositivo, a SEME encaminhou o documento, onde foi aprovado o Parecer CME/SG N 07, de 06 de agosto de 2020, que "Aprova o Plano de Ação da Secretaria Municipal de Educação de São Gabriel/RS para o desenvolvimento de atividades pedagógicas não presenciais às Escolas Municipais, durante o período de suspensão das aulas presenciais, em decorrência da pandemia do coronavírus (COVID-19)".

Devido a continuidade da suspensão das aulas presenciais e aproximação do final do ano, foram encaminhados os Ofícios SEME No 107, 108, 109 e 110, de 02 de outubro de 2020, solicitando ao CME informações para encerramento do Ano Letivo 2020 e orientações para planejamento do Ano Letivo 2021. Como resultado foi aprovado o Parecer CME/SG $\mathrm{N}^{\circ}$ 14, de 30 de novembro de 2020, que "Orienta o Sistema Municipal de Ensino de São Gabriel/RS para encerrar o ano letivo 2020 e fixar diretrizes para o ano letivo 2021, face à excepcionalidade da pandemia da COVID-19".

Além da Ordem de Serviço $N^{\circ}$ 002/2020 (20 de março), foram emitidas também as Ordens de Serviço N 003/2020 (27 de abril), N 004/2020 (01 de junho), Nº05/2020 (01 


\section{A Gestão Educacional da Educação do Campo durante os Tempos de Pandemia no município de São Gabriel/RS/Brasil}

de julho), $\mathrm{N}^{\circ}$ 006/2020 (01 de outubro), $\mathrm{N}^{\circ}$ 007/2020 (26 de outubro) e $\mathrm{N}^{\circ}$ 008/2020 (10 de dezembro), que ordenaram o funcionamento da rede municipal de ensino durante o Ano Letivo de 2020. Após o encerramento do Ano Letivo 2020, cumprindo o disposto no Parecer CME/SG No 14/2020, a SEME encaminhou o Relatório Final de Monitoramento e Acompanhamento das atividades realizadas no período de excepcionalidade, com o número e porcentagem de estudantes aprovados e evadidos por turma, para o Ensino Fundamental, Médio e Técnico e com o número e porcentagem de crianças que realizaram ou não as atividades não presenciais na Educação Infantil.

O Ano Letivo de 2021 iniciou ainda em janeiro, com a SEME protocolando o Plano de Ação Pedagógica, através do Ofício SEME N¹5, de 29 de janeiro de 2021, cumprindo a orientação do Parecer CME/SG No 14 , de 30 de novembro de 2020, sendo aprovado pelo Parecer CME/SG No 005, de 19 de fevereiro de 2021, que "Aprova o Plano de Ação Pedagógica, do ano letivo de 2021, da Secretaria Municipal de Educação de São Gabriel/RS, para o desenvolvimento de atividades pedagógicas".

Com a presença da região em bandeira laranja no Mapa de Distanciamento Controlado do Rio Grande do Sul, a administração pública de São Gabriel aprovou o Decreto Executivo $\mathrm{N}^{\circ} 10$, de 04 de fevereiro de 2021, que permitiu a abertura da educação no modelo de Ensino Híbrido para as Escolas de Educação Básica. Situação reforçada nos Decretos Executivos $\mathrm{N}^{\circ}$ 13/2021 (08 de fevereiro), $\mathrm{N}^{\circ}$ 16/2021 (09 de fevereiro) e $\mathrm{N}^{\circ} 19 / 2021$ (15 de fevereiro), que mantiveram a educação aberta no modelo de Ensino Híbrido.

Porém, com a alteração no cenário da pandemia no município e o ingresso da região na bandeira vermelha no Mapa de Distanciamento Controlado do Rio Grande do Sul, levaram a proibição das aulas presenciais nas redes públicas e privadas do município de São Gabriel, do período de 23 de fevereiro até 1 de março, pelo Decreto Executivo $N^{\circ}$ 020, de 23 de fevereiro de 2021.

Para organizar o funcionamento das atividades pedagógicas não presenciais, com a continuidade da suspensão das aulas presenciais em 2021, denominado de Ensino Remoto, foi elaborada a Ordem de Serviço $N^{\circ}$ 001, de 24 de fevereiro de 2021. A partir do ingresso do município na bandeira preta no Mapa de Distanciamento Controlado, houve a aprovação do Decreto Executivo $\mathrm{N}^{\circ}$ 022, de 27 de fevereiro, reforçando que a educação seguiria o Modelo de Operação de "Ensino Remoto" e Teto de Operação de Empregados em “Teletrabalho ou Presencial Restrito exclusivo para a equipe necessária à manutenção 


\section{A Gestão Educacional da Educação do Campo durante os Tempos de Pandemia no município de São Gabriel/RS/Brasil}

mínima essencial do acesso à educação (por exemplo, operação da plataforma de educação ou entrega de material em formato físico, sob agendamento)".

Esse contexto foi reforçado no Decreto Executivo No 030/2021 (de 06 de março de 2021), no Decreto Executivo No 037/2021 (de 15 de março de 2021), no Decreto Executivo $\mathrm{N}^{\mathrm{o}}$ 043/2021 (de 22 de março de 2021) e no Decreto Executivo $\mathrm{N}^{\mathrm{o}}$ 054/2021 (de 10 de abril de 2021).

\section{Atividades Pedagógicas Não Presenciais nas Escolas do Campo}

O Ano Letivo de 2020, que iniciou no dia 01 de março, teve apenas 18 dias de aulas presenciais e o restante com o desenvolvimento de Atividades Pedagógicas Não Presenciais. Na semana da suspensão das aulas presenciais (16 a 18 de março de 2020), as Escolas Municipais do Campo encaminharam atividades extras para os estudantes.

Constatado a permanência da pandemia, foi realizado a entrega das primeiras atividades no dia 30 de março, onde utilizou-se da Ordem de Serviço $\mathrm{N}^{\circ}$ 002/2020, que determinou que "os professores devem disponibilizar aos estudantes, trabalhos quinzenais" e que "as escolas devem entregar as atividades imediatamente após a suspensão das aulas, priorizando o acesso e oferta da educação", sendo que "no caso das Escolas do Campo, respeitando as suas peculiaridades, deve ser adotado um regime que atenda a essa determinação, no menor tempo possível".

O regime adotado foi de envio em períodos quinzenais, encaminhado pelo transporte escolar público e terceirizado disponível, entregue no tradicional local de embarque ou na residência dos estudantes. No planejamento das atividades, a Ordem de Serviço Nº 003/2020 trouxe que "os professores são referência no processo de ensino e de aprendizagem, assim, cabe a eles elaborar atividades adequadas ao estudante" e ainda reforçou "primando pela adoção de temáticas e adaptações curriculares relacionado ao contexto familiar e local, que favoreça o seu interesse em realizá-lo".

O contexto da Educação do Campo recebeu espaço importante no Parecer CME/SG $\mathrm{N}^{\mathrm{o}} 006 / 2020$, mencionando que:

A diversidade e singularidade das populações do campo, o contexto das condições de acessibilidade (distância, meios de transporte e condições de trafegabilidade) e os aspectos socioculturais/socioeconômicos, exigem a adoção de múltiplas alternativas e estratégias para a oferta de atividades pedagógicas não presenciais, no período de excepcionalidade. 


\section{A Gestão Educacional da Educação do Campo durante os Tempos de Pandemia no município de São Gabriel/RS/Brasil}

O Parecer ainda destacou que "deve-se priorizar o planejamento de atividades que agregue o contexto familiar do aluno e seu vínculo com a terra, através de elementos de produção econômica, aspectos culturais e modo de vida, criando mecanismo de promoção dos objetivos de aprendizagens". Quando da adoção de atividades pedagógicas não presenciais, "exige a garantia dos conceitos de acesso democrático e de equidade pelas populações do campo, respeitando as suas peculiaridades", com "ampla estrutura de logística para que os estudantes e suas famílias tenham acesso as atividades".

\section{Projeto "São Gabriel - minha cidade educadora"}

O ano de 2020 marcou, além da pandemia, o ingresso do município de São Gabriel na Associação Internacional de Cidades Educadoras (AICE). Iniciativa de cunho administrativo, que teve início em agosto de 2019, através da Secretaria Municipal de Educação (SEME), que aprofundou teoricamente o conceito, contatou pesquisadores da área, cumpriu os requisitos (criação da Lei Municipal de Cidades Educadoras, preenchimento do Termo de Adesão solicitando admissão, aceite dos princípios da Carta das Cidades Educadoras e pagamento da Quota Anual 2020) e recebeu o título de Cidade Educadora (Figura 03), em 11 de março de 2020 , tornando-se a $9^{\circ}$ no RS, $21^{\circ}$ no Brasil e a $505^{\circ}$ cidade no mundo (em 2021, já são 10 no RS, 22 no Brasil e 518 no mundo).

Figura 03 - Logo de São Gabriel Cidade Educadora.

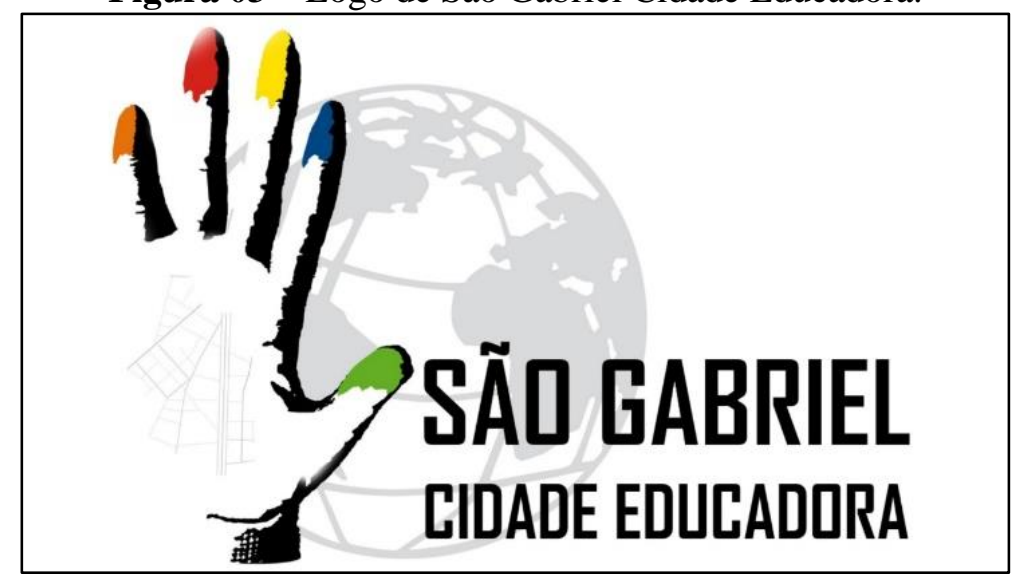

Fonte: SEME (2020).

Para conhecimento, utilizando do principal documento sobre o assunto, a Carta das Cidades Educadoras da Declaração de Barcelona (1990), definiu Cidade Educadora: 


\section{A Gestão Educacional da Educação do Campo durante os Tempos de Pandemia no município de São Gabriel/RS/Brasil}

A cidade será educadora quando reconheça, exerça e desenvolva, para além das suas funções tradicionais (económica, social, política e de prestação de serviços), uma função educadora, isto é, quando assuma uma intencionalidade e responsabilidade, cujo objectivo seja a formação, promoção e desenvolvimento de todos os seus habitantes, a começar pelas crianças e pelos jovens (AICE, 1994).

Para consolidação em São Gabriel, três aspectos foram considerados: 1 responsabilidade e investimento do governo local na educação; 2 - bases históricas e culturais, com bens materiais e imateriais; 3 - atividades e eventos executados em âmbito local, pelos diferentes atores sociais. Inclui-se também os títulos de "Último Reduto dos Carreteiros", "Atenas Rio-Grandense", "Terra dos Marechais" e "Princesa das Coxilhas".

Seguindo o planejamento, após o ingresso na AICE, iniciaria a inserção do conceito no currículo escolar, anexando os princípios da Carta das Cidades Educadoras no fazer pedagógico escolar, servindo de guia no planejamento, emergindo práticas docentes individuais e coletivas, de valorização dos saberes, do tempo e do espaço dos estudantes.

Porém, quando houve a confirmação do ingresso do município em março, estávamos no princípio da pandemia e a administração pública não realizou a divulgação. A situação de calamidade pública continuou e aliado as incertezas vinculadas ao planejamento das atividades pedagógicas, a Secretaria Municipal de Educação divulgou oficialmente no dia 22 de maio de 2020, e concomitante, como forma de desenvolver o conceito de Cidade Educadora nas Escolas Municipais e contribuir no trabalho pedagógico dos professores no momento, foi criado o projeto intitulado de "São Gabriel - minha cidade educadora".

A ação estava estruturada em três fases: Fase 1 denominada de "O lugar de onde eu falo" (refletir sobre o contexto sociocultural em que vivem, minha casa e minha comunidade); Fase 2 de "A identidade da minha cidade" (pesquisar e compreender as bases históricas e culturais de São Gabriel/RS); e Fase 3 de "A cidade que me forma e me respeita" (promover e proporcionar a definição de território educativos na constituição da formação integral dos sujeitos).

Em junho/julho de 2020 foi executado a Fase 1, onde contribuiu para que o professor pensasse ações incorporando o olhar sensível e observador dos próprios alunos sobre os seus elementos proximais, como a residência, a família, a comunidade, aspectos previstos nos princípios do conceito de Cidade Educadora (Figura 04). Como as aulas presenciais estavam suspensas, o projeto contribuiu para nortear os professores no planejamento das atividades pedagógicas não presenciais, em particular nas Escolas do Campo. 


\section{A Gestão Educacional da Educação do Campo durante os Tempos de Pandemia no município de São Gabriel/RS/Brasil}

Figura 04 - Mosaico do Projeto "São Gabriel - minha cidade educadora" na EMCEF Ernesto José Annoni, da proposta de confecção de maquete do lugar preferido da residência.

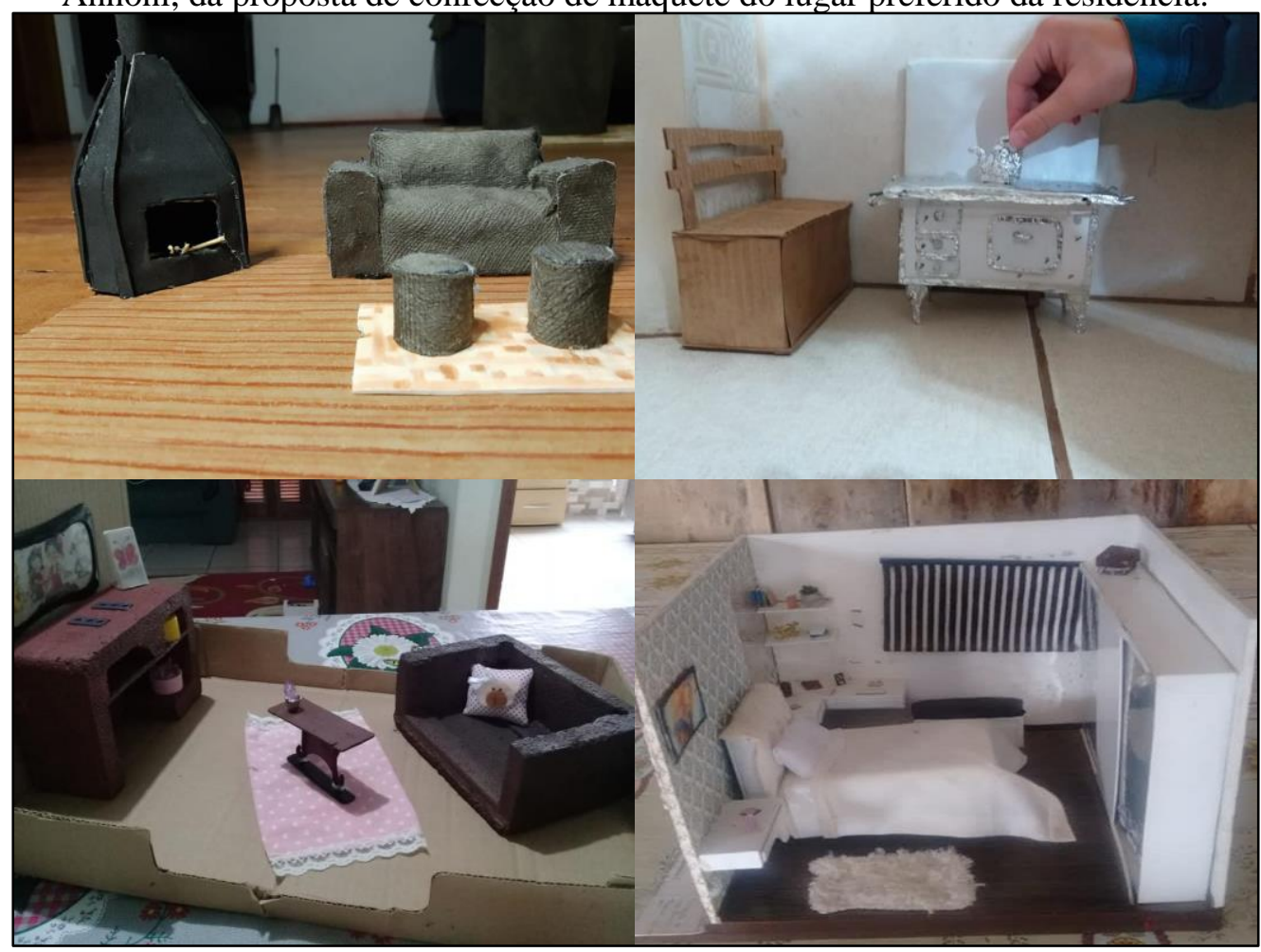

Fonte: SEME (2020).

As Fases 2 e 3 do projeto não foram executadas, pois após as publicações do Conselho Nacional de Educação e do Conselho Municipal de Educação, que regulamentou as atividades pedagógicas durante a suspensão das aulas presenciais e previu o cômputo da carga horária desse período para fins de calendário escolar, a partir de agosto (segundo semestre letivo do ano) foi solicitado às escolas o aprofundamento teórico dos currículos dos anos escolares, dos componentes curriculares e das áreas do conhecimento, para a finalização do ano em dezembro.

\section{Projeto Rádio Educação às Escolas do Campo}

A suspensão das aulas presenciais desafiou os professores em planejar as atividades pedagógicas não presenciais. Entre os aspectos a serem considerados durante os planejamentos, estavam o de manter vínculo com os estudantes; os limites de avançar nos conteúdos; qualidade e quantidade das atividades; processos de monitoramento e avaliação das atividades; aspectos emocionais e psicológicos; distanciamento da comunidade escolar; e, aumento dos números de óbitos e positivados para a COVID-19, sem previsão de retorno das aulas presenciais. Esse cenário complexo e de incertezas, contribuiu para a criação de 


\section{A Gestão Educacional da Educação do Campo durante os Tempos de Pandemia no município de São Gabriel/RS/Brasil}

novas iniciativas, como a proposição do Projeto Rádio Educação (Cartaz do Projeto na Figura 05), com metodologias pedagógicas adaptadas ao contexto atual.

Figura 05 - Cartaz do Projeto Rádio Educação das Escolas do Campo
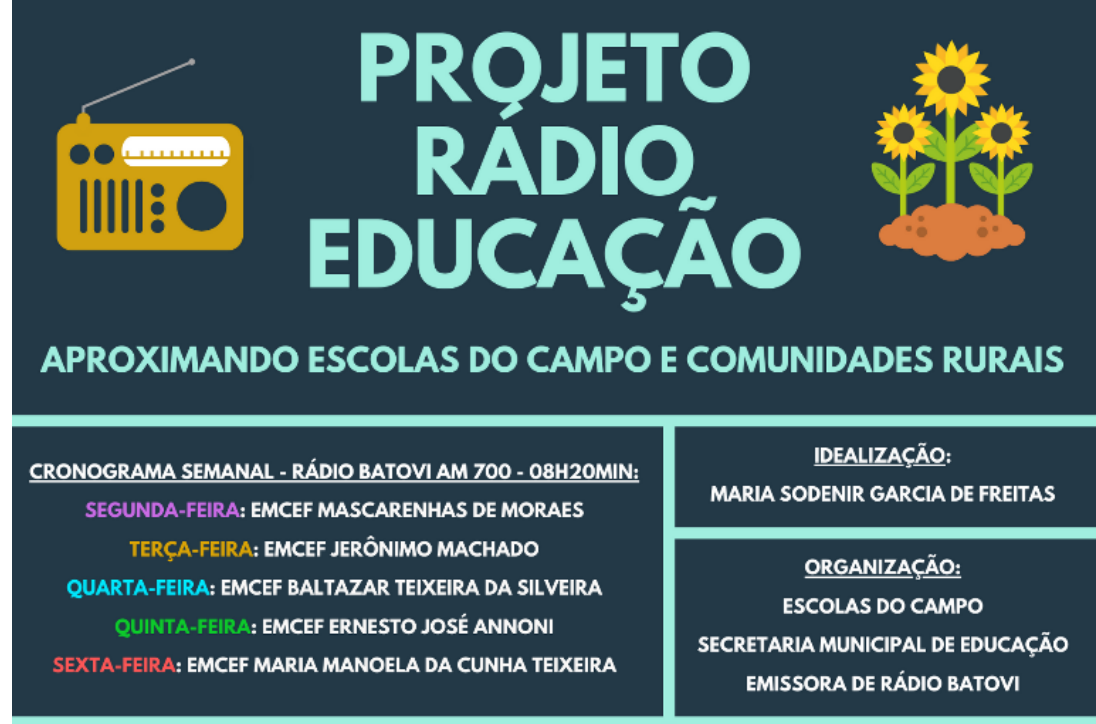

Fonte: SEME (2020).

O projeto foi idealizado pela diretora da EMCEF Mascarenhas de Moraes, professora Maria Sodenir Garcia de Freitas, e realizado com apoio e organização das Escolas do Campo, Secretaria Municipal de Educação e Emissora de Rádio Batovi, com posterior ingresso da Emissora de Rádio Tchê São Gabriel. A proposta teve como objetivo aproximar Escolas do Campo e Comunidades Rurais, durante o período de pandemia, com mensagens, informações e conhecimento pelas emissoras de rádio de locais, e teve sua divulgação oficial no dia 22 de junho de 2020.

A execução do projeto contava inicialmente com inserções diárias às 08 horas e 20 minutos na Emissora de Rádio Batovi, com duração total de 10 minutos, sob a responsabilidade das Escolas do Campo. Das 8 instituições de ensino do campo, as 3 Escolas Multisseriadas não participaram da execução por possuírem um único docente, ficando os dias da semana fixos para as 5 Escolas Polos, por possuírem maior grupo de profissionais, constituídos por direção e professores, da Educação Infantil ao Ensino Fundamental completo.

Os primeiros programas foram executados pelas equipes diretivas das escolas, com mensagens dos integrantes da Secretaria Municipal de Educação, apresentando o projeto e 108 


\section{A Gestão Educacional da Educação do Campo durante os Tempos de Pandemia no município de São Gabriel/RS/Brasil}

convidando os membros das comunidades escolares a acompanharem diariamente o programa. Após, as produções dos áudios ficaram a cargo dos professores, inicialmente utilizados para suas apresentações individuais, explicação das atividades enviadas e abordagem do conceito de Cidade Educadora, e aos poucos avançando em temas e conteúdos dos componentes curriculares. Os programas eram planejados e organizados pelas direções, enviados no dia anterior a transmissão à emissora.

Considerando o objetivo do projeto, a metodologia utilizada pelos professores buscava atingir os estudantes matriculados nas Escolas do Campo, mas também aproximar todos os integrantes das comunidades escolares. Os professores foram desafiados em produzir áudios para além de seus alunos, levando as instituições de ensino para todos do grupo familiar, para as residências das comunidades rurais.

Nesse sentido que iniciou um trabalho diversificado, com contação de histórias; lendas e parlendas do folclore brasileiro; contos e causos da história local; e a partir do dia 13 de agosto, utilizou-se das principais datas comemorativas de cada semana, como tema gerador coletivo, que através de um trabalho interdisciplinar, cada professor abordava o tema considerando o seu componente curricular e sua área de atuação na produção dos áudios. Ao mesmo tempo, buscou unificar os programas de rádio com as atividades enviadas presencialmente.

O projeto obteve um expressivo engajamento por parte dos professores das escolas e por parte das comunidades escolares. No contexto local, uma segunda emissora se interessou pela proposta e convidou o projeto, com a primeira transmissão às 20 horas no dia 24 de julho, na Emissora de Rádio Tchê São Gabriel.

O encerramento do projeto aconteceu no dia 27 de novembro, com agradecimento da Secretaria Municipal de Educação ao empenho das direções e professores das Escolas do Campo, na organização dos programas, para levar mensagens, informações e conhecimentos, em um gesto de acolhimento e carinho, mantendo o vínculo entre escola e comunidade pelas emissoras de rádio locais.

O Projeto Rádio Educação teve ótima repercussão no cenário estadual, sendo matéria (Figura 06) no Programa Bom Dia Rio Grande da RBS TV RS ${ }^{1}$ (emissora filiada à Rede Globo), no dia 06 de agosto, sendo reconhecido como importante iniciativa de enfrentamento

\footnotetext{
1 Link da reportagem no Programa Bom Dia Rio Grande da RBS TV RS (06 de agosto de 2020): https://globoplay.globo.com/v/8755930/. 


\section{A Gestão Educacional da Educação do Campo durante os Tempos de Pandemia no município de São Gabriel/RS/Brasil}

da pandemia na área da educação, que auxilia na aproximação entre escola e comunidades escolares, para o desenvolvimento das atividades pedagógicas.

Figura 06 - Matéria do Projeto Rádio Educação das Escolas do Campo de São Gabriel no Programa Bom Dia Rio Grande da RBS TV RS

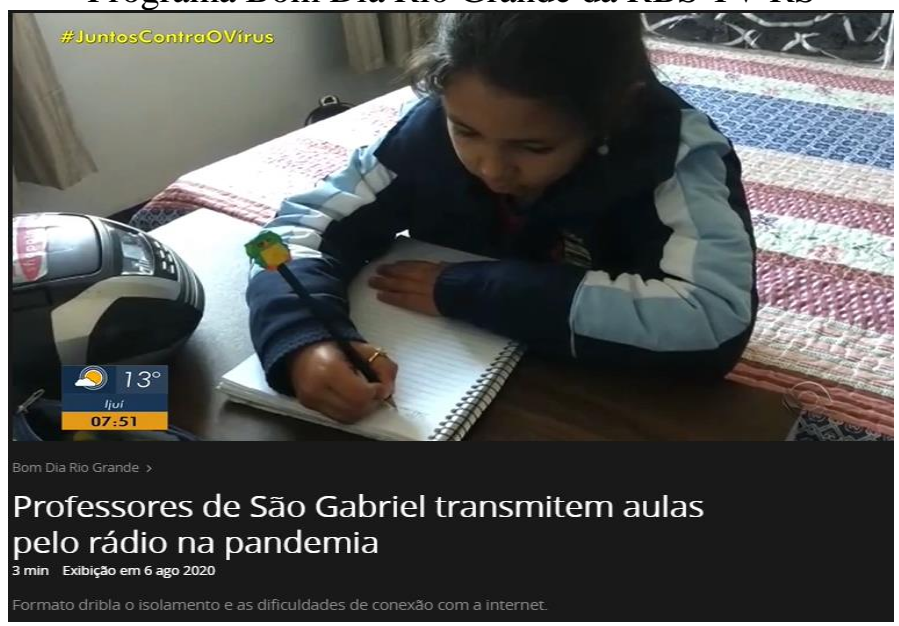

Fonte: SEME (2020).

Também houve publicidade em outros veículos de imprensa (Figura 07), com destaque no Jornal Diário de Santa Maria ${ }^{2}$ (online), no Jornal GaúchaZH ${ }^{3}$ (impresso e online) e no Jornal Online Coletiva Net de Porto Alegre/RS ${ }^{4}$ (online).

${ }^{2}$ Link da reportagem no Jornal Diário de Santa Maria: https://bityli.com/aPPru.

${ }^{3}$ Link da reportagem no Jornal GaúchaZH: https://bityli.com/uCAeK.

${ }^{4}$ Link da reportagem no Jornal Online Coletiva Net de Porto Alegre/RS: https://bityli.com/kLVns.

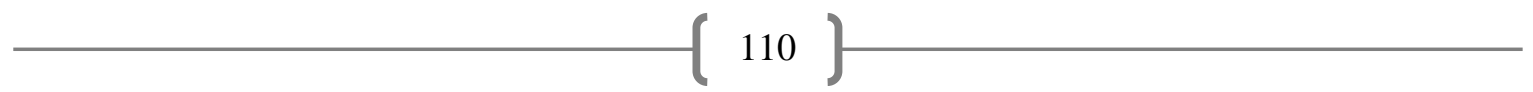

RIET- ISSN 2676-0355, Dourados, v. 2, n. 2, p. 94 a 114, jan./jun., 2021 


\section{A Gestão Educacional da Educação do Campo durante os Tempos de Pandemia no município de São Gabriel/RS/Brasil}

Figura 07 - Mosaico de notícias do Projeto Rádio Educação na impressa estadual.

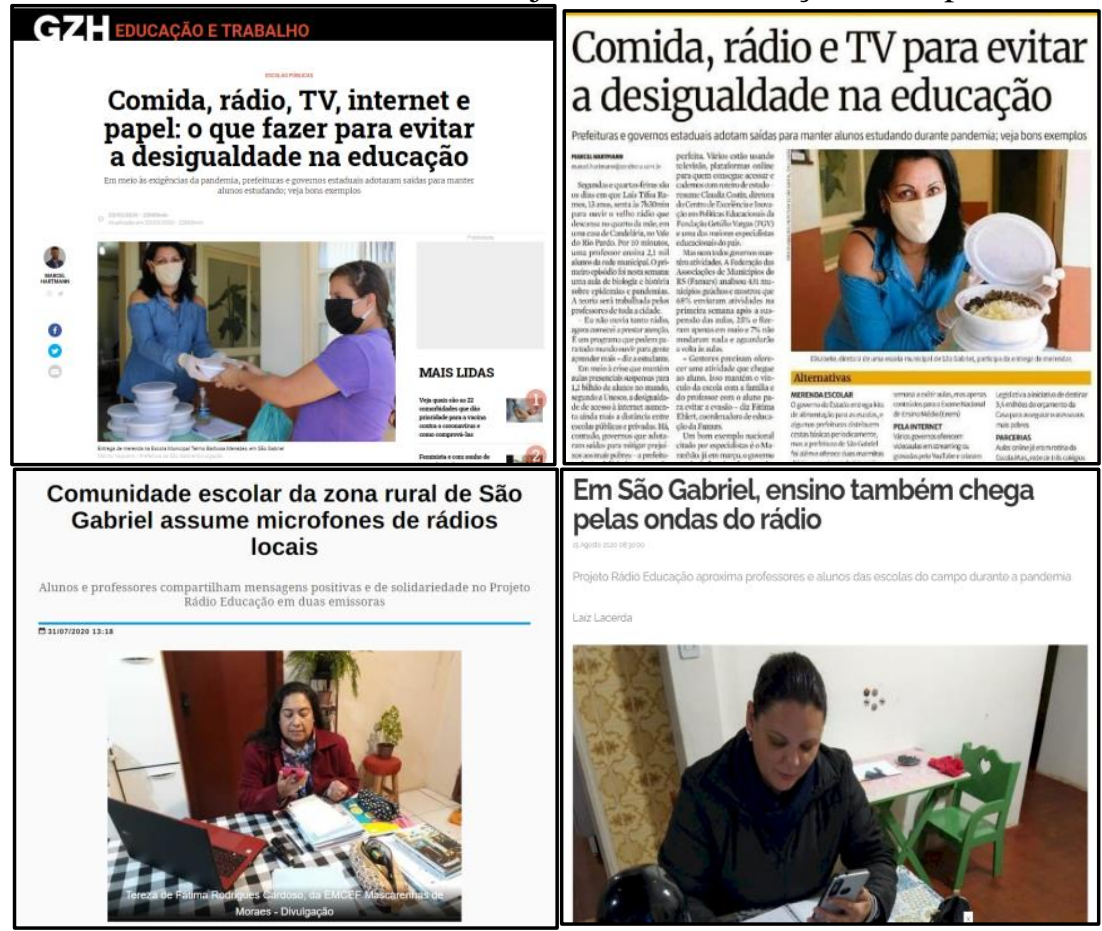

Fonte: SEME (2020).

\section{Considerações finais}

A pandemia desafiou o mundo a repensar as suas organizações habituais. Como forma de enfrentar ao momento, cada setor procurou criar alternativas, estratégias e procedimentos para continuar agindo em seus locais de atuação, adaptando ao contexto, incluindo a área da educação.

Quando da suspensão das aulas presenciais em março de 2020, o principal objetivo da Secretaria Municipal de Educação foi de garantir a continuidade do acesso ao direito a educação, previsto na Constituição Federal (1988), e de manter o vínculo entre escola, direção e professores, com os estudantes e suas famílias. Desta forma, foi adotado o modelo de Atividades Pedagógicas Não Presenciais, atualmente designado como Ensino Remoto.

A Educação do Campo, historicamente foi relegada ao segundo plano na agenda política nacional. Porém, considerando a característica da Escola do Campo como referência social local e que se constituí como importante espaço de encontro dos integrantes da comunidade e consequentemente de produção de saberes, essas instituições de ensino, não poderiam ficar desassistidos durante esse período. Além disso, por vezes, a escola é o único serviço público de acesso das comunidades rurais.

\section{1}

RIET- ISSN 2676-0355, Dourados, v. 2, n. 2, p. 94 a 114, jan./jun., 2021 


\section{A Gestão Educacional da Educação do Campo durante os Tempos de Pandemia no município de São Gabriel/RS/Brasil}

Na semana da suspensão das aulas presenciais, as Escolas do Campo encaminharam atividades pedagógicas extras, antes do início do período. Quando decretado oficialmente a suspensão, sucederam-se atividades planejadas, em períodos quinzenais, até o final do ano letivo, encaminhadas pelo transporte escolar e entregues nos tradicionais locais de embarque ou na residência dos estudantes.

As primeiras atividades tiveram como única finalidade o de manter o vínculo. Porém, com a continuidade da suspensão, o período de incertezas e professores preocupados com as atividades que estavam sendo planejadas, que surgiu a proposta do Projeto "São Gabriel minha cidade educadora" em maio de 2020. O objetivo era de contribuir com subsídios conceituais às iniciativas e ações de cunho pedagógico por parte dos professores, podendo criar atividades que contemplassem o conceito de Cidade Educadora e, principalmente, que provocasse um novo olhar para o contexto local dos estudantes, sendo esse contexto muito importante ao considerar a necessidade do resgate e valorização da história e da cultura das comunidades rurais nas Escolas do Campo.

Em junho, intensificam-se as dificuldades vinculadas ao contato entre escola e comunidade, e expõe o baixo acesso as tecnologias pelas comunidades rurais, tanto de aparelhos, como de sinal de telefonia e de internet, por exemplo. Nesse sentido, que surge o Projeto Rádio Educação, pois as ondas de rádio é a tecnologia mais democrática na área rural do município, chegando a 100\% das residências dos estudantes das Escolas do Campo.

O Rádio Educação, criado pela Diretora Maria Sodenir Garcia de Freitas, organizado e executado pelas direções e pelos professores das Escolas do Campo, serviu para manter o vínculo com os alunos e suas famílias, através de uma nova metodologia. Além disso, possibilitou o envio de importantes mensagens, informações, conhecimento, histórias sobre diferentes assuntos e temáticas.

O grande desafio encontrado no desenvolvimento do projeto, considerando o planejamento e a produção dos programas, foi de conseguir chegar no público-alvo. Por se tratar de um canal de comunicação gratuito e democrático, que o acesso ocorria por diferentes pessoas, ou seja, que os ouvintes não eram exclusivamente os estudantes, as direções e os professores tiveram que adaptar os conteúdos e a linguagem dos programas, para chegar a todos os integrantes das comunidades rurais.

Para finalizar, percebe-se que São Gabriel foi um dos primeiros municípios gaúchos a definir as Atividades Pedagógicas Não Presenciais na rede de ensino, antes mesmo de 


\section{A Gestão Educacional da Educação do Campo durante os Tempos de Pandemia no município de São Gabriel/RS/Brasil}

existir normatizavas sobre o assunto, que garantisse o cômputo da carga horária para o cumprimento do calendário escolar. Além disso, todas as orientações e determinações foram devidamente planejadas e documentadas, como forma de organizar o funcionamento do período.

Registramos a importância para o contexto educacional local da existência do Sistema Municipal de Ensino, com o funcionamento efetivo do órgão do Conselho Municipal de Educação (CME), que possui caráter deliberativo, consultivo, normativo, fiscalizador, propositivo e mobilizador. Durante a pandemia e a suspensão das aulas presenciais, o CME vem acompanhando todas as ações executadas na rede municipal de ensino, apreciando e deliberando sobre o assunto, como forma de contribuir no funcionamento da educação.

Por fim, apesar do período de pandemia, o município de São Gabriel encontrou formas legais e com definição de normas próprias, para a continuidade da oferta da educação na rede municipal de ensino, com um olhar sensível e humano às Escolas do Campo. Saber que a Educação do Campo, mesmo em tempo de retrocesso educacional, em razão da calamidade pública vinculado a pandemia, vem se mantendo viva, ativa, articulada e propondo alternativas de enfretamento do momento, demonstra que São Gabriel está consolidada como local que se faz Educação do Campo e, principalmente, buscando atender com equidade e qualidade as comunidades rurais.

\section{Referências}

BRASIL. Constituição da República Federativa do Brasil. Brasília: Câmara dos Deputados, 1988.

BRASIL. Lei de Diretrizes e Bases (LDB). Lei no 9.394/96. Brasília: MEC, 1996.

BRASIL. Diretrizes Operacionais para a Educação Básica nas Escolas do Campo. Resolução CNE/CEB n 1/2002. Brasília: MEC/SECAD, 2002.

BRASIL. Diretrizes complementares, normas e princípios para o desenvolvimento de políticas públicas de atendimento da Educação Básica do Campo. Resolução CNE/CEB no 2/2008. Brasília: MEC/SECAD, 2008.

BRASIL. Diretrizes Curriculares Nacionais Gerais para a Educação Básica. Resolução CNE/CEB n 4/2010. Brasília: MEC, 2010a.

BRASIL. Política de Educação do Campo e o Programa Nacional de Educação na Reforma Agrária. Decreto n ${ }^{\circ}$ 7.352/2010. Brasília: MEC, 2010 b. 


\section{A Gestão Educacional da Educação do Campo durante os Tempos de Pandemia no município de São Gabriel/RS/Brasil}

CALDART, Roseli Salete. Educação do Campo. In: CALDART, Roseli Salete et al (Org.). Dicionário da Educação do Campo. Rio de Janeiro - São Paulo: Expressão Popular, 2012.

CHIZZOTTI, Antônio. Pesquisas em Ciências Humanas e Sociais. São Paulo, Cortez, 1998.

GIL, Antonio Carlos. Métodos e técnicas de pesquisa social. 6. ed. São Paulo: Atlas, 2008.

KOLLING, Edgar Jorge; NERY, Irmão Israel José; MOLINA, Castagna Molina (org.). Por uma educação básica do campo. Brasília: Articulação Nacional por uma Educação do Campo, 1999.

PASTORIO, Eduardo. Alteração da Nomenclatura das Escolas do Campo: dispositivos legais e teóricos. In: SOARES, Jeferson Rosa. Educação Brasil. Chapecó/SC: Livrologia, 2019. v. 7, p. 215-231.

PASTORIO, Eduardo. Nucleação das Escolas do Campo: o caso do município de São Gabriel/RS. 2015. 162 f. Dissertação (Mestrado em Geografia) - Programa de Pós-Graduação em Geografia, Universidade Federal de Santa Maria, Santa Maria, 2015.

SÃO GABRIEL. Projeto minha Cidade Educadora. Secretaria Municipal de Educação de São Gabriel. São Gabriel/RS: SEME/SG, 2020.

SÃO GABRIEL. Dispõe sobre as Diretrizes Curriculares para Educação do Campo, no Sistema Municipal de Ensino de São Gabriel/RS. Resolução CME/SG No 009/2019. São Gabriel: CME, 2019.

SÃO GABRIEL. Pareceres. Parecer CME/SG No 06/2020, No 07/2020, No 14/2020 e No 005/2021. São Gabriel: CME, 2020/2021. Disponível em: https://cmedsg.wixsite.com/cmesg/pareceres. SÃO GABRIEL. Ordens de Serviço. Ordem de Serviço SEME No 002/2020, No 003/2020, N ${ }^{\circ}$ 004/2020, $N^{\circ} 005 / 2020, N^{\circ} 006 / 2020, N^{\circ} 007 / 2020, N^{\circ} 008 / 2020$ e No 001/2021. São Gabriel: SEME, 2020/2021.

SÃO GABRIEL. Decretos Executivos. Decreto Executivo $N^{\circ} 024 / 2020, N^{\circ} 10 / 2021, N^{\circ} 13 / 2021$, $\mathrm{N}^{\circ} 16 / 2021, \mathrm{~N}^{\circ} 19 / 2021, \mathrm{~N}^{\circ} 020 / 2021, \mathrm{~N}^{\circ} 022 / 2021, \mathrm{~N}^{\circ} 030 / 2021, \mathrm{~N}^{\circ} 037 / 2021, \mathrm{~N}^{\circ} 043 / 2021$ e $\mathrm{N}^{\circ}$ 054/2021. São Gabriel: Prefeitura Municipal, 2020/2021. Disponível em: https://www.saogabriel.rs.gov.br/Portal/comunidade/publicacoesLegais.html.

SÃO GABRIEL. Secretaria Municipal de Educação. Página Oficial no Facebook. São Gabriel: SEME, 2020. Disponível em: https://www.facebook.com/seme.saogabriel.

SÃO GABRIEL. Conselho Municipal de Educação. Site Oficial. São Gabriel: CME, 2021. Disponível: https://cmedsg.wixsite.com/cmesg.

THIOLLENT, Michel. Metodologia da pesquisa-ação. 14. ed. São Paulo: Cortez, 2005.

YIN, Robert K. Estudo de Caso: planejamento e método. Porto Alegre: Bookman, 2011.

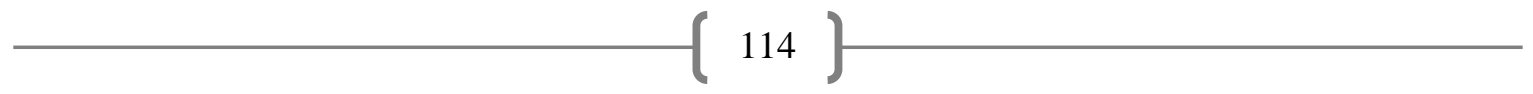

RIET- ISSN 2676-0355, Dourados, v. 2, n. 2, p. 94 a 114, jan./jun., 2021 